\title{
Addictive drugs still best option for attention deficit disorder
}

The most popular medicines for attention deficit hyperactivity disorder (ADHD) are widely abused, according to the latest damning report on the controversial subject.'Abuse-proof' alternatives are increasingly becoming available, but they are not as effective as the addictive medicines, doctors say.

ADHD drugs such as Ritalin and Adderall are stimulants that help to enhance concentration by boosting levels of the 'feel-good' neurotransmitter dopamine- a feature they have in common with cocaine. The number of Ritalin prescriptions soared during the 1990s, but reports on its illegal use quickly began to follow.

The most recent report in February showed that more than 7 million people in the US have abused ADHD stimulants, and as many as 750,000 teenagers and young adults show signs of addiction (Drug Alcohol Depend. published online 15 February 2006; doi:10.1016/j.drugalcdep.200 5.12.011). A US Food and Drug Administration (FDA) panel also warned in February that the stimulants may pose a risk for heart failure.

The warning emerged after reports of 25 deaths and 54 cases of cardiovascular problems in adults and children between 1999 and 2003. Scientists say years of study are needed to understand exactly how the drugs affect the heart.

But psychosocial stimulants are still the best available drugs for quelling common ADHD symptoms such as inattention and hyperactivity, say doctors. "At the end of the day, stimulant medications just work so nicely and people tolerate them really well," says psychiatrist Joel Young, medical director of the Rochester Center

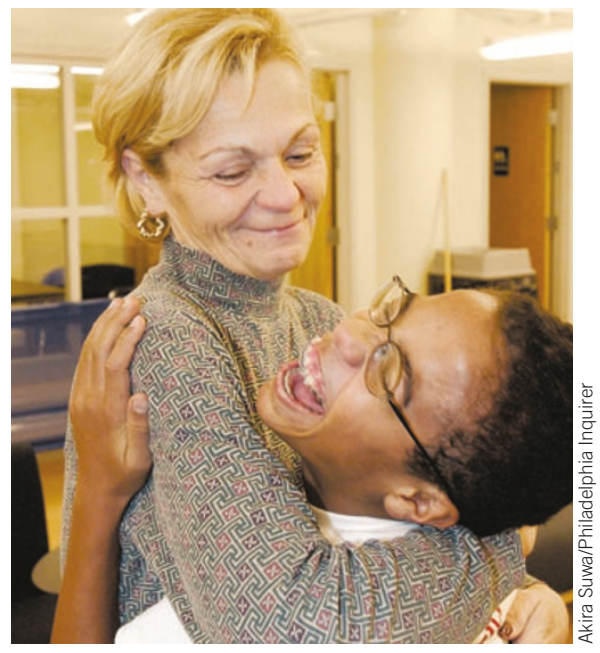

Heavy dose: More than 7 million people in the US have abused drugs for attention deficit disorder.

for Behavioral Medicine in Minnesota.

Partly in response to the stigma surrounding stimulants, a few pharmaceutical companies are developing abuse-proof ADHD treatments. In 2002, Eli Lilly released the nonstimulant Strattera, which boosts concentration by increasing the levels of another mood-regulating neurotransmitter known as norepinephrine.

More recently in March, California-based Cortex Pharmaceuticals announced promising results from phase 2 human trials for its drug CX717, which acts by boosting levels of glutamate, a neurotransmitter involved in learning and memory. Sparlon, a nonstimulant version of the popular sleep-buster drug Provigil, is also expected to receive FDA approval this year.

Drugs that trigger the release of dopamine create pleasant feelings that the brain can begin to crave over time. By targeting norepinephrine, Strattera theoretically skirts the potential for addiction, and was anticipated as a safe alternative to stimulants. But nearly four years after its release, it commands only about $15 \%$ of the market. Last year, the FDA also suggested that Strattera may cause suicidal thoughts in some children.

"Strattera is relatively a bust compared to Ritalin and Adderall," says Lawrence Diller, a behavioral pediatrician in Walnut Creek, California. "Despite massive advertising and educational campaigning by Eli Lilly, the word on the street amongst physicians is that Strattera is a second-choice drug, at least in children."

Drugs such as Strattera and CX717 are unlikely to match the highly effective stimulants, doctors say, and are primarily a choice for people who also suffer from other disorders such as anxiety or who may have a history of substance abuse.

Preliminary studies indicate that fast-acting versions of stimulant drugs-which induce euphoric feelings right away-may be more prone to abuse. If further studies hold up such findings, says Lenard Adler, director of the adult ADHD program at the New York University Medical Center, the industry could switch to longer-acting formulations of the same drugs. Companies might also develop new ways of delivering the drugs that would enable the safer use of stimulants.

Paroma Basu, Madison

\section{Spain takes aim at better clinical research schemes}

The Spanish Health Ministry has launched a program to boost the country's research output. The scheme will allow physicians to give up some of their clinical responsibilities in order to focus on research, but some researchers say it's only a bandage fix for a larger problem.

Most biomedical research in Spain is carried out in public hospitals. But because physicians have to devote most of their time to clinical duties, the scheme is an important step toward boosting translational research. "I've saluted the measure with enthusiasm since it opens a key door-the recognition of the research time of researchers with healthcare contracts," says Josep M. Antó, director of the Barcelona Municipal Institute of Medical Research.

Physicians who wanted to do research previously did so on their own time. The new scheme, launched in January, will primarily benefit those clinicians who are leading research projects funded by the health and science ministries, but will be expanded in the next few years. The health ministry's Carlos III Health Institute (CHI), the primary funding agency for biomedical research, is expected to formalize the agreement with the regional health authorities.

Initially, 55 staff physicians with a $\mathrm{PhD}$ and a recognized research trajectory will be able to reduce their bedside time by onehalf. The CHI plans to provide $\$ 1.7$ million to the regional governments to cover the salary of substitute physicians.

But the scheme unfairly benefits only a small fraction of physician-scientists, says
Rafael Molina, a clinical biochemist at the Hospital Clínic of Barcelona. Molina says all physicians should be allowed to spend up to $25 \%$ of their time on research.

The new program "might create two categories of hospital physicians, with the 'elite' being represented by those engaged in research," he says. Getting doctors involved in research may also affect their teaching duties, and further impoverish an already overburdened system, others caution.

Long-term solutions for improving Spain's research will require the government to adopt radical reforms in the curriculum for medicine and other life sciences, says Antó, who notes that there is no model for a research-based career in Spain. "The problem seems to be deeply rooted," he says. Xavier Bosch, Barcelona 